University of Wollongong

Research Online

Faculty of Social Sciences - Papers (Archive) Faculty of Arts, Social Sciences \& Humanities

2015

Eleven design-based principles to facilitate the adoption of internet technologies in Indigenous communities

Michelle J. Eady

University of Wollongong, meady@uow.edu.au

Follow this and additional works at: https://ro.uow.edu.au/sspapers

Part of the Education Commons, and the Social and Behavioral Sciences Commons

Research Online is the open access institutional repository for the University of Wollongong. For further information contact the UOW Library: research-pubs@uow.edu.au 


\title{
Eleven design-based principles to facilitate the adoption of internet technologies in Indigenous communities
}

\begin{abstract}
Internationally, the internet is a critical component of many projects that aim to improve literacy and build skills in indigenous communities. It is claimed that online platforms provide flexible learning opportunities to suit individual learner schedules and needs, enabling them to learn in 'anytime, anywhere' environments. However, good intentions and a learning platform deemed suitable by non-indigenous people do not necessarily lead to successful user outcomes. There is a need to understand how Western culture influences the design and implementation of online projects with Indigenous communities and to avoid technological colonisation of the local community. Flexibility, understanding and respect must be at the forefront of projects if they are to be successful. This article suggests 11 design-based principles, derived through design-based research, which guide respectful implementation of internet technologies in indigenous communities.
\end{abstract}

\section{Keywords}

design, principles, facilitate, eleven, adoption, communities, internet, technologies, indigenous

\section{Disciplines}

Education | Social and Behavioral Sciences

\section{Publication Details}

Eady, M. J. (2015). Eleven design-based principles to facilitate the adoption of internet technologies in Indigenous communities. International Journal of Social Media and Interactive Learning Environments, 3 (4), 267-289. 


\title{
Eleven design-based principles to facilitate the adoption of internet technologies in Indigenous communities
}

\author{
Michelle J. Eady \\ School of Education, \\ Faculty of Social Sciences \\ University of Wollongong \\ Northfields Avenue \\ Wollongong, NSW 2522, Australia \\ Email: meady@uow.edu.au
}

\begin{abstract}
Internationally, the Internet is a critical component of many projects that aim to improve literacy and build skills in Indigenous communities. It is claimed that online platforms provide flexible learning opportunities to suit individual learner schedules and needs, enabling them to learn in "anytime, anywhere" environments. However, good intentions and a learning platform deemed suitable by non-Indigenous people do not necessarily lead to successful user outcomes. There is a need to understand how Western culture influences the design and implementation of online projects with Indigenous communities and to avoid technological colonisation of the local community. Flexibility, understanding and respect must be at the forefront of projects if they are to be successful. This article suggests 11 design-based principles, derived through design-based research, which guide respectful implementation of Internet technologies in Indigenous communities.
\end{abstract}

Keywords: Indigenous culture, synchronous technology, design-based research, online learning.

Biographical notes: Michelle is a senior lecturer in Professional Studies in the School of Education at the University of Wollongong. In 2013, she was a recipient of an Australian Office of Teaching and Learning (OLT) teaching excellence award. Her current research focus is quality teacher preparation.

Michelle has lived and worked in remote Canadian and Australian Aboriginal communities. A qualified primary school teacher, she lent her expertise to the Aboriginal adult literacy field for over a decade, and was awarded the Province of Ontario's Council of the Federation of Literacy Award for Innovation in Literacy for her work. She also received the William A. West medal for academic achievement at the Masters level from Lakehead University in Thunder Bay Canada.

Dr Eady has had the pleasure of speaking at conferences worldwide and looks forward to collaborations with colleagues who have a passion for teaching and learning. 


\section{Introduction}

Over recent years, there has been a movement towards the use of Internet technologies to provide greater opportunities for employment development and training. This has encouraged educators worldwide to employ online learning environments as a means of achieving educational aims and goals (Kral, 2010). The online learning movement provides opportunities for novel approaches in a variety of contexts, including students in Early Years through to Year 12, as well as students in training institutions, universities and other tertiary and post-secondary environments.

Despite online learning environments providing increased opportunity for more adult learners globally, there remains a wide difference in skill competency levels between Indigenous and non-Indigenous populations. Many Indigenous communities are disadvantaged by geographical barriers, government policies, language background, poverty, and health and technical insufficiencies (Craig Rushing and Stephens, 2012; Rennie et al., 2013; Taylor, 2012). It is often expensive and impractical to provide in situ, face-to- face teaching, so options that make use of the Internet need to be explored. However, Indigenous communities need assistance to develop literacy skills if they are to make full use of the potential learning opportunities that can be delivered via the Internet.

There has been some success in online learning for Indigenous adults on a global level, such as the Good Learning Anywhere (GLA) project in Ontario, Canada (English, 2013). It has helped identify areas of interest, such as online science courses for urban Indigenous youth (Bang et al., 2013), and potential business and agriculture enterprises (Rennie et al., 2013). However, there is limited research focusing on the approaches that have achieved authentic online learning experiences for Indigenous adults. This study aims to contribute a framework of best practices to the research literature by presenting design-based principles which can be applied when introducing Internet technologies to adult learners inIndigenous communities.

\section{Literature Review}

There are approximately 370 million Indigenous people in the world, comprising almost $6 \%$ of the world's population (United Nations, 2009). Mexico, Bolivia, Peru, Ecuador, Guatemala, Canada and the United States have the largest Indigenous populations. Several Indigenous communities are dispersed throughout Oceania, with the largest concentration in Papua New Guinea (United Nations Educational, Scientific and Cultural Organization (UNESCO), 2006). In Australia, the Indigenous population is widely distributed, with many Indigenous language groups across the continent in both urban and remote settings.

Although international statistics are limited and difficult to obtain, there is a significant difference in literacy rates between Indigenous and non-Indigenous people across the globe. Researchers and educators agree this is due to limited access to formal educational opportunities in Indigenous communities (UNESCO, 2006). Education systems have attempted to respond with strategies that focus on inclusivity and increased access, however, substantial disparity remains in the levels of educational skill attainment between Indigenous adults and the general adult population. In Australia, for example, there are lower levels of educational participation for Indigenous Aboriginal people than non-Aboriginal people across all sectors (Australian Bureau of Statistics, 2010; Australian Bureau of Statistics, 2011). Only $35.9 \%$ of Aboriginal adults have completed Year 12 , compared to $67.3 \%$ of their non-Aboriginal counterparts (Australian Bureau of Statistics, 2011). Most of the Aboriginal adults who have completed Year 12 are located in urban areas (Australian Bureau of Statistics, 2010), suggesting that Aboriginal adults living in remote and rural areas have not had access to the same educational opportunities as other Australians (Altman and Fogarty, 2010).This study aims to:

1. explore how best to introduce and incorporate technology-based learning while 
respecting a specific Australian Indigenous cultural context and;

2. develop some general principles to inform and support the online teaching of adult literacy in Indigenous communities.

The research investigated how online live-time technology could meet Indigenous adults' literacy needs within an Australian Aboriginal community. Literacy needs were identified by stakeholders including community practitioners and Indigenous community members. The study also investigated how existing technologies were employed.

The findings were used to develop guidelines for best practices to build adult literacy in Indigenous communities. It was anticipated that a model would be developed to inform future research and policy.

\section{Methodology}

Two groups of participants were recruited for this study. The first consisted of practitioners who work with people from Indigenous communities and/or with matters of Indigenous education, in either a face-to-face or a computer-based capacity. These practitioners were located in various states across Australia and together brought a wealth of educational backgrounds and experience to the study.

The second group of participants, who formed a community focus group, were members of a specific Indigenous community from a region in South Australia. Focus groups were an important research strategy, given the importance of group interaction and oral tradition in Aboriginal society (George, 1997). The 13 people who volunteered to participate in the community focus group meeting varied in age, gender, employment status and literacy levels. Two were university graduates, five had completed some of a TAFE (Technical and FurtherEducation) training course and six had not completed Year 12. The eight women and five men ranged in age from 17 to sixty-seven. Their community was considered rural or remote as it is at least 20 kilometres from any adjacent towns and approximately 200 kilometres from the nearest major city centre.

Every effort was made to ensure that the community was involved throughout the research process. Battiste (2008) suggests that for research methods to be respectful, Indigenous communities must have direct input in "developing and defining research practices and projects that relate to them" (p.503). After achieving ethics approval for this research project, the community and council were approached to gain permission and support. Great care was taken to ensure the researcher was allowed and welcomed into the community. When the council manager granted the researcher permission to be present in the community, it was considered a privilege and treated with great respect.

The school principal was instrumental in the researcher being accepted into the community. The principal's mother, a respected community Elder, took the researcher around the town and introduced community members. These meetings took place in busy local venues such as the health building, the school, the TAFE and included knocking on other Elders' doors and being invited to tea. The Elder also shared stories of the land, local history and people.

The researcher requested a meeting with the community council in order to gain support from council members. During this meeting the researcher presented similar projects conducted in Canada and explained the purpose of the research and the significance of community involvement. The council was very supportive with one man saying, "I think that this is a great idea for our people. To give them the opportunity to learn like this is important." Two women on the other side of the table whispered to one another for a bit, nodded their heads and one said to the researcher, "You have our full support." The council members were asked to spread the word about the first focus group and to forward suggestions of suitableadditions to the group. The council also asked the researcher to draft a letter that would be signed by all to show support of the project. 
The researcher hung signs around the town advertising the focus group and extended a welcome for anyone to join. Community members were asked to volunteer their time over two months, working together to create a meaningful literacy experience and learning to use a synchronous platform which was available for the broader community to use. All focus group and council members received a copy of the community members' participant information sheet, which the researcher read aloud, and signed a community member participation consent form. Figure 1, below, depicts the strategy for the recruitment of volunteer community members.

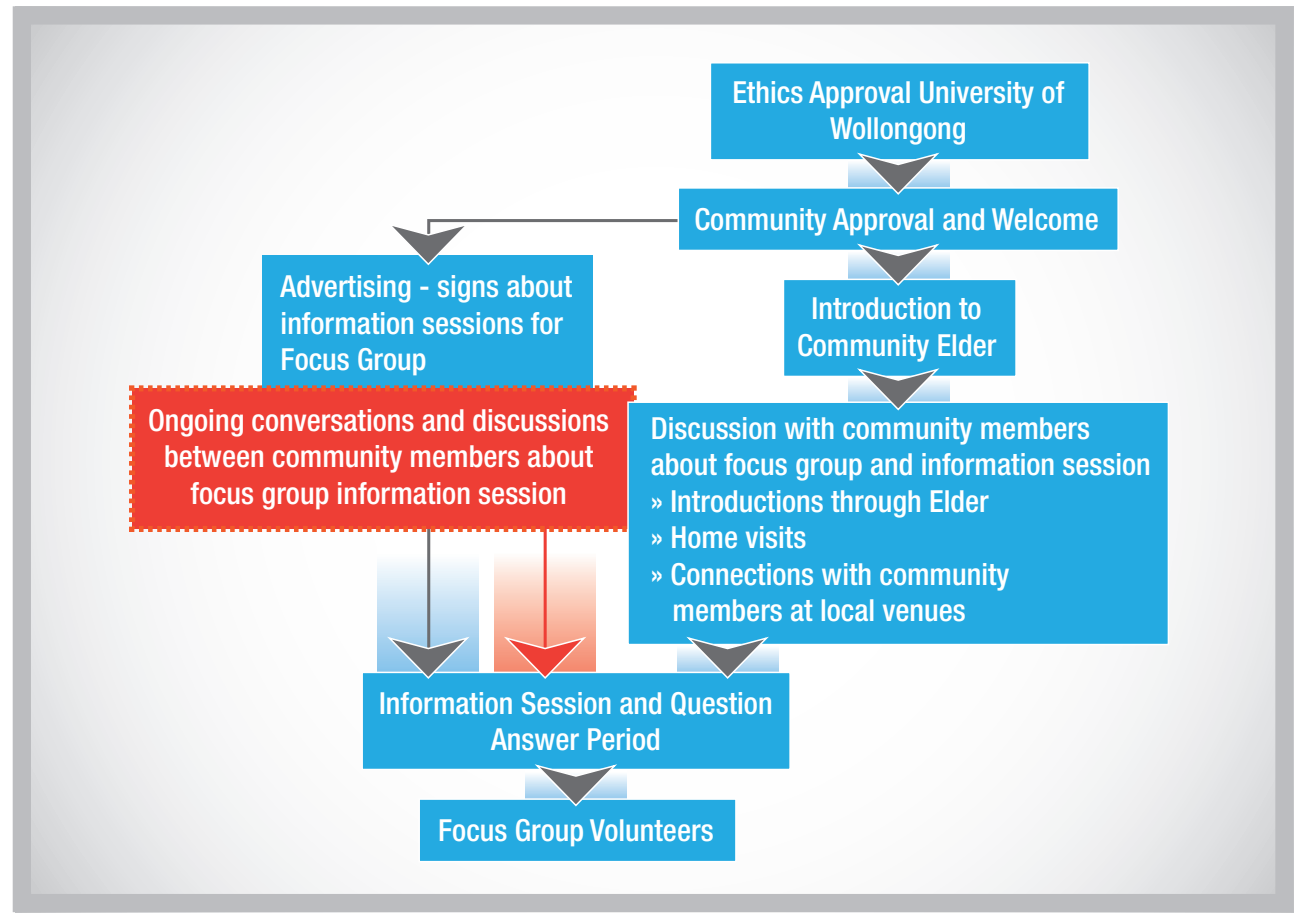

Figure 1: Strategy for the recruitment of volunteer community members

This research project was a qualitative study which used a design-based research approach (van den Akker et al., 2006). Wang and Hannafin (2005) define this as "a systematic but flexible methodology aimed to improve educational practices through iterative analysis, design, development, and implementation, based on collaboration among researchers and practitioners in real-world settings and leading to contextually sensitive design principles and theories" (p.6-7). 


\section{Design-Based Research}

Analysis of Practical

Problems by

Researchers and

Practitioners in

Collaboration
Development of

Solutions informed

by Existing Design

Principles and

Technological

Innovations
Iterative Cycles of

Testing and

Refinement of

Solutions in

Practice
Reflection to

Produce "Design

Principles" and

Enhance Solution

Implementation

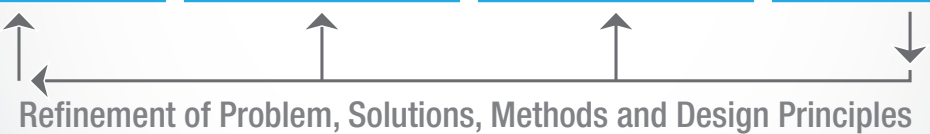

Figure 2: Four phases of the design-based research process (Reeves, 2006)

As depicted in Figure 2, above, there are four phases in the process of design-based research according to Reeves (2006). In the first phase, practical problems are analysed and draft guiding principles are established after consideration of the literature and in collaboration with stakeholders. In the second phase, a solution - informed by existing principles - is developed. In the third phase, iterative cycles of testing the solution, reflecting, and refining the draft guiding principles occurs. Finally, in the fourth phase, further reflection results in enhanced design principles and solutions to the identified problem.

Design-based research offered advantages to this study as it integrates practice and theory, while valuing interactive relationships between researchers and practitioners. The approach enabled the researcher to incorporate data collected through interviews and focus groups with input from Aboriginal community members who participated in forming research questions and drafting the guiding principles. This approach enabled the researcher to follow the suggestions of Battiste (2008) and Christie (2004) by respecting Indigenous research methods and knowledge. Figure 3, below, depicts design-based research in relation to this study and describes what occurs at each phase of the research project. 


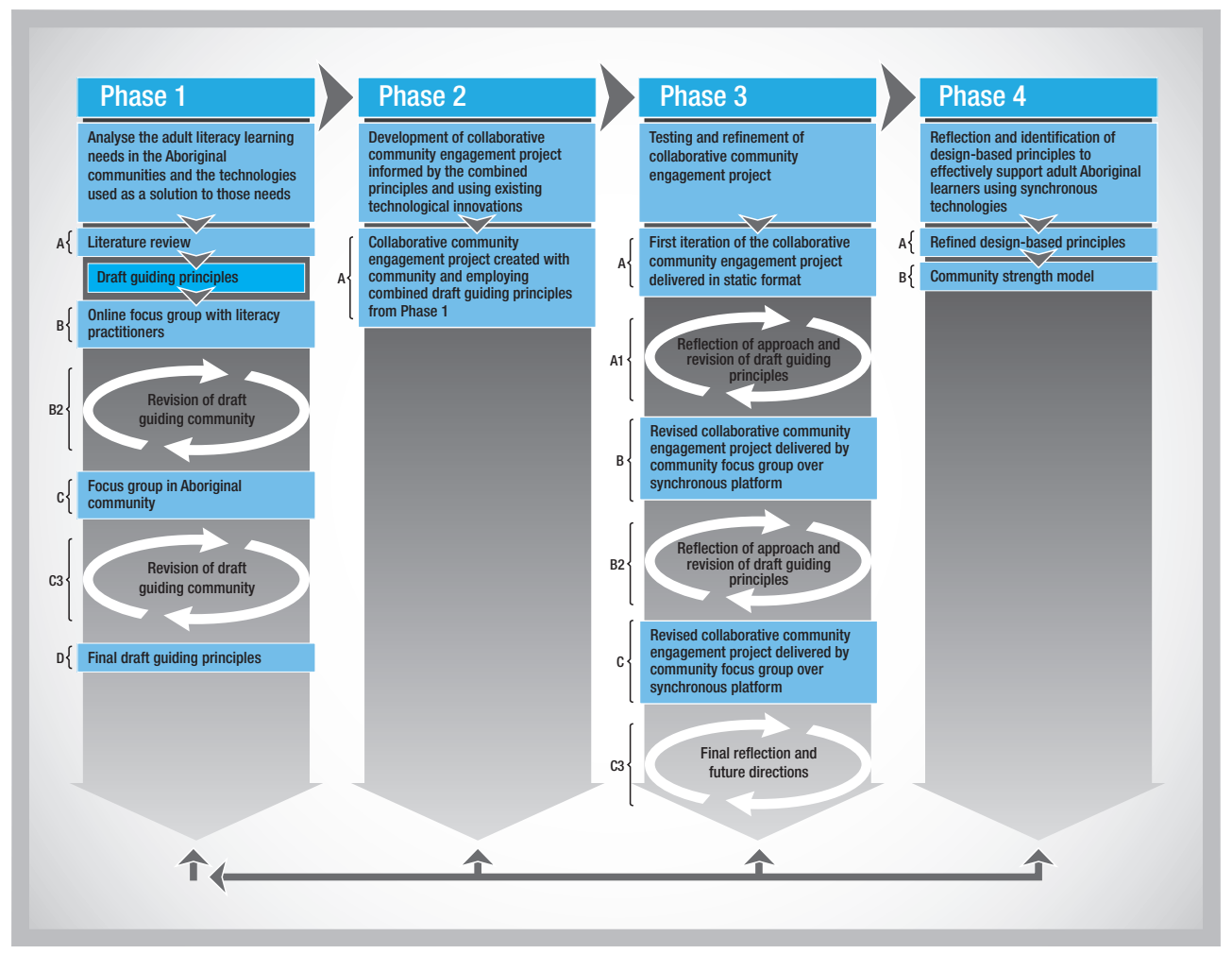

Figure 3: Phases of this design-based research project (based on Reeves (2006))

\section{Results and Discussion}

This section is organised according to the four phases of the design-based research problem and discusses the findings at each of these phases, as depicted in Figure 2.

\section{Phase 1: Analysis of the problem}

The literature suggested nine common elements relating to the successful implementation of online learning technologies with Indigenous learners. The nine elements, outlined below, were called draft guiding principles. They were enhanced and refined during each the process of the research.

\section{Practitioner skills and awareness of Aboriginal literacy levels}

Teaching in a distance format requires practitioners to invest additional time and effort to build rapport and trust with their learners (O'Callaghan, 2005). As well as incorporating learning methodologies congruent with learning styles of Aboriginal adults, instructors must also be well versed in Information and Curriculum Technology and troubleshooting (Brescia and Daily, 2007).

\section{Opportunities to participate in a community of learning.}

Synchronous learning technology, when accessible to remote communities, alleviates the impacts of social isolation on adult learners (Dixon et al., 2008). Rather than struggling in isolation and segregation, Indigenous adults have an opportunity to participate in learning 
activities and social networking in a culturally affirming learning environment (McDonald et al., 2006; Smith et al., 2008). Further, real-time participant interaction offers an acceptable alternative for Indigenous adults, who are typically not comfortable in a face-to-face classroom in a Western-based learning institution (Australian Institute for Social Research, 2006; Brescia and Daily, 2007; Greenall, 2005).

\section{Relevant content}

Projects with Indigenous learners report that the use of curricula containing relevant content, which proves meaningful and applicable to the lives of their learners, is directly related to learner retention and learning outcomes achievement (Greenall, 2005; McDonald et al., 2006). It is important to note that literacy is more than the mechanical skills of language, but provides a sense of ownership and a means of power of position in society that can also result in an authentic voice for Indigenous learners. Miller and Harris (2005), and O'Callaghan (2005), suggest that literacy learning is a tool that empowers learners to 'interact meaningfully'with society.

\section{Cultural inclusion}

The literature indicates that learning technologies need to support and enhance Indigenous traditions, values and practices. Online content should be easily translated and the curriculum should include content relevant to the geographical area and cultural context of the learner (Australian Institute for Social Research, 2006; Crossing Boundaries National Council, 2005; Donovan, 2007; O'Callaghan, 2005). McGlusky and Thucker (2006) assert that literacy practitioners need to demonstrate cultural competency, which includes an understanding of the culture and living conditions of the local Indigenous community, as a superficial, global understanding is inadequate. They claim that this is necessary when delivering any type of learning programs to Indigenous communities. By learning about the communities on an individual level and adjusting curriculum accordingly, program staff members are able to offer courses that more accurately serve the socio-economic and political realities of each community (Australian Institute for Social Research, 2006).

\section{Accessible, suitable and reliable technology}

Synchronous learning must be supported by technology that is suitable for community conditions where it is being used. Factors that impede the availability of Information and Curriculum Technology resources in Indigenous communities often relate to social issues (i.e. only given to the privileged), cultural considerations (i.e. inappropriate content) and fiscal constraints (Brescia and Daily, 2007).

Technological support is also a relevant factor. If technical support is not available to maintain and operate the most current forms of Information and Curriculum Technology, it will have little use to the community (Brescia and Daily, 2007).

\section{Intergenerational community involvement and consultation}

The Indigenous community must be included during the development and delivery phases of synchronous learning initiatives through the presence of instructors, needs and technical capacity (McGlusky and Thucker, 2006; Tankard and O'Kelly, 2009). O'Callaghan (2005) cites community involvement as the most important element in achieving outcomes stating, "The more control and authority a community has in training, the more successful that training will be" (p.7). 
Christie (2004) wrote about the need to acknowledge and respect the community's ownership of its Indigenous knowledge when it is shared through Information and Curriculum Technology, stating:

“...its architecture and structure, its search processes and interfaces, its ownership and uses must also reflect and support context specific Indigenous ways of being and knowing, and people's control over their own knowledge" (p.5).

These guidelines and monitoring procedures ensure that the cultural integrity of the content is maintained while keeping the value system of the people it represents intact.

Involving community Elders respects the various cultural, social and linguistic aspects of individual communities and can help to prevent the one- size-fits-all programming that often results when incorporating Aboriginal culture into learning programs (Australian Institute for Social Research, 2006; Eagles et al., 2005). The 2005-2006 Australian Flexible Learning Framework's Indigenous Engagement Project (Callan and Bowman, 2010) suggested:

"Drawing on the expertise of community members, and involving them in troubleshooting as problems arise, facilitates ownership of projects by communities and leads to better outcomes for learners" (McDonald et al., 2006, p.19).Hughes and Dallwitz (2007) state:

"Any IT strategy dealing with cultural material must avoid any perception of technological colonisation and loss of local ownership" (p.156). From his work in Indigenous communities in Australia, Christie (2004) has observed:

"When new perspectives come into a community - as when white Australians come and introduce new systems, new ideas or new technologies - these are assessed and valued and embraced in the context of community sharing and working together" (Christie, 2004, p.2).

Similarly, consultations with local Elders assist in educating non-Indigenous project staff in the cultural elements unique to individual communities, including language and traditional knowledge (Australian Institute for Social Research, 2006; Battiste, 2008; Eagles et al., 2005)

\section{Positive relationships, mentoring and technical support}

It is recommended that a student mentor is onsite throughout the learning process, when possible, to provide tutoring and technological support as needed (Bamblett, 2005; Porter and Sturm, 2006). The Sunchild project has led the way in this area in its program in Alberta, Canada (Greenall, 2005). One strategy was to send a community member from each remote site to an Information and Curriculum Technology support training program, so that before online programs began there was someone with technical skills to support learners in each community.

The literature proposes learner retention and motivation are directly related to the relationship students have with their instructor, particularly in the distance-learning 
environment (DuCharme-Hansen and Dupin-Bryant, 2005; Greenall, 2005). This becomes especially important in communities where literacy services are limited as the instructor often becomes a learning lifeline to Indigenous learners in remote locations. Many instructors who have taught Indigenous adults in a synchronous learning milieu have reported higher levels of learner success when they invest time and energy in learner engagement (Australian Institute for Social Research, 2006).

Vygotsky's concept of Zone of Proximal Development supports placing emphasis on the instructor's role when teaching Indigenous adult learners at a distance. Fani and Ghaemi (2011) describe the Zone of Proximal Development as the difference between what a learner can do independently and what can be accomplished cognitively with guided support from more knowledgeable others. The adult literacy practitioner who uses a synchronous platform with Indigenous learners is engaged in a comparable process. It has been found that it is important to have as much support as possible for learners in remote communities. Greenall (2005), Bamblett (2005) and Porter and Sturm (2006) suggest a student mentor should be available onsite for learner, technological and emotional support.

\section{Promoting community-based learning}

Learning in their own community has been suggested as a predictor of educational success for Indigenous adults. Indigenous learners generally prefer to work collaboratively, traditionally valuing kinship and the aspects of community over individual learning contexts (El Sayed et al., 2011). Research validates that by accessing learning opportunities from their home, communities can assist in overcoming the isolation experienced by Indigenous adults, which even in urban settings is a common deterrent to successful completion of academic studies (Alberta's Commission on Learning, 2008; Australian Institute for Social Research, 2006; Greenall, 2005). However, studying at home is not the total solution to learner success. Indigenous learners who stay in their communities also face the challenges of family, work and cultural commitments that may impede the progress of their studies (Eady, 2010). It is due to these challenges that a combination of synchronous and asynchronous platforms are recommended to enable learner access to recorded class sessions and capacity to contribute to discussion groups at their convenience (Australian Institute for Social Research, 2006; Eady, 2010; Greenall, 2005).

\section{Genuine partnerships with the government for bottom-up learning}

Overall, the literature indicates a lack of fiscal dedication at the government level to support literacy training in Indigenous communities (McGlusky and Thucker, 2006; O'Callaghan, 2005; Sawyer, 2004). Research suggests that this external bureaucracy often impedes communities taking charge of their own learning strategies and causes them to hesitate in partnering with government-funded literacy agencies (Greenall, 2005).

\section{Additions to Draft Guiding Principles Based on Consultations with Practitioners}

The literacy practitioners, who were trained and experienced in working with Aboriginal learners, identified four categories of need - relevant to literacy - with the communities they work with. These included the need to understand learners' complexities, that improvements were needed across all literacy skills, that children needed community support and that the community needed stronger literacy to achieve a stronger voice. The practitioners also identified three categories of successful approaches used in Aboriginal contexts, including using culturally relevant approaches and materials, a focus on community development and the facilitation of a mentorship program. 
The practitioners identified several types of technology currently used for different literacy activities and the flexibility it could bring to learning. Literacy practitioners each play their own unique role in the communities in which they work. The practitioners who participated in this focus group identified the roles they thought they played and how those roles might change with the continued influx of computers and the increased use of technology.

During the research, the draft guiding principles that were created from the literature were refined in order to achieve principles that support effective and successful synchronous learning experiences for adult Aboriginal learners. Input from the literacy practitioner and data collected from practitioners informed revisions to the draft. Some of the draft guiding principles were expanded and a tenth principle was added.

\section{Community goals, directions and development}

The data collected from the practitioners suggest a starting point for synchronous learning includes understanding the community's goals and directions. The use of technology can be seen as a tool of development for the community and help to better link the community to the outside world.

\section{Further Changes to Draft Guiding Principles}

Additional information came from a volunteer community focus group member who shared their views on literacy needs in their Aboriginal community. The member identified literacy to be the actual mechanics of language and how language works, as well as providing a voice for the community which can be used to empower. The identified needs for the community included support for learning activities, technology skills, and employability readiness.

Reeves (2006) suggests developing draft guiding principles based on the literature and input from practitioners. In the context of this research, input from the Aboriginal community member was a critical addition and data collected from community members informed further revisions to the draft guiding principles.

\section{Final Version of Draft Guiding Principles Based on Consultations with Practitioners}

At the end of the second phase of the research there were 10 draft guiding principles to take through Reeves' (2006) iterative cycles (Figure 2). These are presented in the following section.

\section{Develop skills and awareness of Aboriginal learners' profiles}

To effectively use synchronous technology with Aboriginal learners, practitioners need to develop additional technological skills, including Information and Curriculum Technology knowledge and troubleshooting abilities. Of equal importance is an awareness of the literacy levels of Aboriginal learners and their preferred methods of learning, to ensure learning opportunities can be made relevant to the community's needs.

\section{Create opportunities to participate in an online learning community}

Effective participation of Aboriginal learners in online learning communities is more likely to occur when facilitators have an awareness of participants' past learning experiences, encourage and build positive interpersonal relationships, provide opportunities for capacity 
building and foster social networking for learners. These opportunities must be culturally relevant, reflecting local cultural traditions and community values, and take place in the context of unique, shared environments that incorporate local language and Aboriginal ways of knowing and learning.

\section{Utilise relevant content}

Learning experiences using synchronous technologies for Aboriginal learners should make use of relevant, computer-adaptable content. Relevant content is meaningful and applicable to the lives of the learners. More than just mechanical skills and mandated curriculum, relevant content must be created in consultation with the community to result in empowerment, ownership and an authentic voice for the community. Examples of relevant content include:

- enabling an Aboriginal adult to better understand their identity as an Aboriginal person;

- connecting content to cultures and traditions;

- encompassing community values;

- learning that grows from community knowledge; and

- helping to gain employment.

As a result, relevant content can help community learners negotiate, explain, defend, share and uphold what is important to them.

\section{Value cultural inclusion}

In any synchronous learning setting there should always be consideration of culture in the instruction and implementation. Understanding the culture, geographic area, living conditions, socio-economic status and language are critical steps in working to achieve cultural inclusivity. It is important to have a relationship with the community on an individual basis. More than culture, it is important to understand Aboriginal ways of knowing and learning in each community. The ideal scenario would be implementing an Aboriginal curriculum that is created from within the community, with community involvement, and delivered by community members for community members. The learning material and resources would also be community-centred and include many opportunities to practise local language.

\section{Support implementation of technology that is accepted, accessible, suitable and reliable}

A first step in employing the use of any technology in an Aboriginal community setting is ensuring that the technology is accepted into the community. The way the technology is introduced is a critical part of online learning. The technology itself must be suitable, taking into account:

- cultural values;

- social issues;

- fiscal constraints; and

- technological support.

It is important for the community to consider the technology to be beneficial, which can be achieved through:

- social networking and family connections; 
- community capacity building;

- links to other communities; and

- professional training for community mentors.

\section{Foster intergenerational community involvement and consultation}

It is important to ensure that the community has an internal locus of control when using online technology. According to Aboriginal ways of knowing and learning, learning is something that belongs to you, which starts before you are born and continues through your life. Learning together should be promoted in order to build stronger relationships within the community and to strengthen the community itself. Development of online learning tasks should include Elders and children alike promoting a whole-family approach.

\section{Build positive relationships, mentoring and technical support}

Several types of mentors and practitioners are needed in the synchronous learning process in order to achieve sustainable programs.

- Onsite mentors may travel to the community to support community learners.

- Peer mentors follow learners who work together to support one another.

- Community mentors can provide fellow community members with support and upskilling.

- Technical support mentors provide technical help within the community.

- Tutors are external employees who come to the community to support learners. Alternatively, learners travel outside of the community to see them.

- Liaison officers work to build better relationships between communities.

- Practitioner mentors provide support and assistance to practitioners who work within Aboriginal communities

Relationships between these mentors and practitioners have a significant influence on learner retention and motivation. Instructors must be able to:

- make time for relationship building and gaining trust;

- have energy to put into engaging learners;

- be approachable;

- offer academic and emotional support;

- scaffold computer skills;

- show respect for community and members;

- be sensitive towards learners;

- take time to understand the community; and

- ensure they have down-time in order to avoid burnout.

\section{Promote community-based learning}

It is important for community-based learning to provide opportunities to bring community members together in collaborative ways. Aboriginal culture in general values kinship and togetherness and learning something new, such as computer technology, within the community promotes these values. Promoting community-based learning enables community members to see the benefits of learning with technology first-hand. Using blended approaches to learning such as asynchronous, synchronous and face-to-face opportunities within communities will allow for self-directed, comfortable and convenient learning environments. Using Aboriginal strengths in these contexts, such as oral storytelling, song, the Dreaming, and local language, 
creates an atmosphere of familiarity for learners.

\section{Cultivate genuine partnerships with government}

Working with technology requires funding for capital, maintenance, training and support. In order to provide opportunities for synchronous learning that is meaningful, relevant, empowering and situated in real-life settings, more work must be done in developing meaningful communication with stakeholders who influence funding. These relationships can help community members to rebuild a sense of worth and power of position in the wider community.

\section{Understand community goals, directions and development}

Synchronous learning tools should be used as community-development support-systems. When employed effectively, these tools will provide links to the outside world and make communities more self-sufficient. It is important to understand the goals, direction and development issues that are valued in the community on an individual level, so that synchronous technologies can support those visions.

\section{Phase 2: Developing a Solution}

The second phase of the research was the development of a framework and solution to the identified problem, informed by existing principles and technological innovations (Reeves, 2006). For the purpose of this study the term 'collaborative community-engagement project' was used to replace the term 'solution'. This choice of terminology was made to alleviate any negative connotation associated with the word 'solution' while working in an Aboriginal setting. A collaborative community-engagement project was built on the foundation of the 10 draft guiding principles drawn from the findings of Phase 1 of the research. The 'existing technological innovation' (Reeves, 2006) employed during this phase of the research was the application of an online synchronous tool called CENTRAC.

Even though the Indigenous community had access to the CENTRA $\odot$ platform, it was never used, as there was no stable Internet connection. The timing of this project was favourable, as the community had resolved their Internet connectivity issues at the onset of the project. The community council offered a room for the project as the school computers did not have a reliable Internet signal and all were firewall protected, so only administrators could download software. This would have made it difficult to install and use CENTRAC) on these computers.

CENTRA@ was introduced to council members during the initial meeting through a PowerPoint presentation. The presentation included photographs of Aboriginal learners from a project in Canada, where the researcher had previously worked, and detailed the types of courses that they had taken and how these opportunities had impacted on them.

Community members welcomed the opportunity and there was great anticipation about the opportunity to learn more about the Internet and computers in general. This approach enhanced draft guiding principle number seven (build positive relationships, mentoring and technical support). It was necessary to gain respect from the community, and show respect for the community by asking permission to be on the land. It was also essential to gain approval to meet and gain support from the council. The community members who attended the initial meetings were very interested in how the researcher had utilised the technology with other Aboriginal cultures and the council members were eager to participate in a project that would see similar results for their community. 


\section{Phase 3: Iterations of the Collaborative Community Project}

The circuitous nature of the design-based research approach resulted in elaborate and intricate data collection over three iterations of the collaborative community project. Through these iterative cycles, the researcher and participants refined the community-engagement project according to information interpreted from data collected at the end of each cycle. The project was then implemented again. To begin Phase 3, participants took part in synchronous platform training sessions, to prepare to present their work in the online environment. The project was presented in the following ways.

Table 1: Iterations of the community engagement project

\begin{tabular}{|l|l|l|l|}
\hline & Iteration One & Iteration Two & Iteration Three \\
\hline $\begin{array}{l}\text { Mode of } \\
\text { Presentation }\end{array}$ & $\begin{array}{l}\text { A static recorded } \\
\text { presentation of the } \\
\text { project }\end{array}$ & $\begin{array}{l}\text { A live-time version } \\
\text { of the project } \\
\text { using synchronous } \\
\text { technology }\end{array}$ & $\begin{array}{l}\text { A live-time version } \\
\text { of the project } \\
\text { using synchronous } \\
\text { technology }\end{array}$ \\
\hline Audience & $\begin{array}{l}40 \text { community } \\
\text { members and the } \\
\text { Minister of Education } \\
\text { for the region }\end{array}$ & $\begin{array}{l}\text { 12 Aboriginal Elders } \\
\text { at an Elder care } \\
\text { centre in a nearby } \\
\text { community and three } \\
\text { of the centre's staff } \\
\text { members }\end{array}$ & $\begin{array}{l}\text { Eight University staff } \\
\text { gathered in a video } \\
\text { conferencing room, } \\
\text { one government } \\
\text { member joining } \\
\text { online and one TAFE } \\
\text { member joining } \\
\text { online }\end{array}$ \\
\hline $\begin{array}{l}\text { Numbers in } \\
\text { Audience }\end{array}$ & 40 & 15 & 10 \\
\hline
\end{tabular}

During the first iteration, a PowerPoint version of the collaborative community-engagement project was presented to the community. The focus group was very excited about the decision to show their presentation at a community event and thought it would be a great way to share their message and show what they were able to do. There were about 40 people present in the room, including a prominent government representative, who had a front-row seat. The presentation was shown on a large interactive white board. At the end of the presentation, people in the classroom clapped and cheered.

After the presentation, focus group members conveyed that one lady was worried she "looked stupid" because she couldn't pronounce one of the words in the presentation, so she asked if we could change that word in future. Community members also found and contributed more photographs for future presentations. Other reflection and feedback from community members who viewed the presentation was considered carefully and discussed amongst the focus group members. Once a group consensus was met, the feedback and comments were then used to refine the project for the next time it was presented. This discussion, reflection and modification had a timeframe of approximately two weeks.

The second iteration was presented on the online synchronous platform. This time, the focus group presented their project on the synchronous setting live-time. The audience was a group of twelve Elders and three staff members at the local Elder care centre in one of the neighbouring communities. The presentation at the centre was well received by people who attended and they especially enjoyed hearing the children singing in the presentation. Many positive comments were made and compliments were given to the group for doing such a good job. The presentation also sparked some discussion about the importance of bringing 
back all the languages of Aboriginal people in Australia. Comments were made about it being a time to unite and work together, regardless what language group people belong to. Some of the Elders were very concerned that in the first part of the presentation, the community's history was presented by a person who was not originally from the community. The group agreed and reorganized the presentation to ensure a more appropriate person told the history of the people. The Elders' involvement in critiquing the presentation, which was very important to the focus group members, is another example of generational support in the literacy process. Again, reflection from the community focus group and suggestions from people who attended the presentation, were used to refine the third and final presentation. The importance of Aboriginal ways of knowing and learning, and having Elders who are imparted with Elder education involved in the learning process, was pertinent to this iteration. This was highlighted to the extent that an eleventh draft guiding principle was considered (Embrace Aboriginal ways of knowing and learning through Elder education). This new principle led to draft guiding principles two, four and six being further refined.

The third iteration of the project was also presented on the online synchronous platform took place approximately a week after the second presentation. This iteration was a presentation to academic staff at the University of Wollongong. Aboriginal staff members on campus and at the Aboriginal college affiliated with the university were also invited. One staff member had family connections to the community where the research was taking place. An invitation was also extended to an interested member of the TAFE community who had supported the community, and to a government representative who provided funding in order for this project to take place. This invitation, extended in the hope that continued discussions would lead to more equivalent partnerships, is an example of how third-party liaison is needed to build government awareness and concern for the community (as highlighted in earlier iterations of draft guiding principle nine). One of the focus group members took the lead and asked the university attendees if there were any questions or comments. The TAFE representative thanked the group for the presentation and the work they had done to put it together and said he looked forward to working with the community in the coming months. At the university, one professor expressed to the presenters the positive reactions from everyone in the room.

The government representative also spoke kind words of support and hopes to continue this learning pathway with the community. It was clear in this last iteration of the presentation that the community focus group had employed a bottom-up approach to create a presentation that was about a culturally relevant topic to them. The skills they had acquired through the process instilled a sense of ownership and provided a platform for the community to address the outside world in their own authentic voice. In doing so, the community helped to foster relationships with institutions of higher education and continue discussions with government representatives. In this way, draft guiding principle nine (cultivate genuine partnerships with government) was further refined, as the technology introduced to the community allowed them to connect directly with government representatives and other stakeholders and voice their concerns in an authentic community context. Reflections from the community focus group and suggestions from the attendees were used to provide feedback about the process used and the entire project. Once again, this process generated some refinements to the draftguiding principles. This resulted in 11 design-based principles being applied to the process of creating optimal environments for synchronous learning opportunities in Aboriginal communities. 


\section{Phase 4: Design-based Principles}

This section discusses the 11 design-based principles for establishing optimal learning environments for effective use of technologies to support adult Aboriginal literacy learners.

\section{Develop skills and awareness of Aboriginal learners' profiles}

This principle recommends that practitioners develop technological skills and present themselves in confident, competent, adaptable and flexible ways. An awareness of literacy levels and preferred learning styles is needed to connect with learners and to make learning relevant to the community's needs, learner focused and learner driven. Phase 3 suggests that certain levels of literacy are required for learners to experience success with technology, but there is no need to underestimate the ability of Aboriginal learners. Instead, appropriate expectations of these learners must be carefully considered.

\section{Create opportunities to participate in an online learning community}

The second design-based principle suggests that it is imperative to understand Aboriginal learners' past learning experiences in order to assist them in effectively participating in an online community. These opportunities should include social networking and interpersonal relationships, be culturally relevant, and include local cultural traditions and values. The learners' and the community's current social struggles should also be considered when creating opportunities to participate in an online learning community. Phase 3 suggests that the online community should be fostered through the learning process, which must incorporate opportunities for all parties to share and collaborate in the online environment. Relevant, computer-adaptable content is needed to create successful learning experiences using synchronous technologies for Aboriginal communities. This content must be created in consultation with the community to result in empowerment, ownership, and an authentic voice for the community. Try to employ content that:

- helps Aboriginal adults better understand their identity as an Aboriginal person;

- connects content to cultures and traditions;

- encompasses community values;

- grows from community knowledge;

- assists with gaining employment; and

- has been created in consultation with the community.

\section{Value cultural inclusion}

In any synchronous learning setting, culture should be considered during instruction and implementation stages. This includes geographic area, living conditions, socio-economic status and language group. Achieving cultural inclusion through consultation with the community is important at every level of learning. The aim should always be to implement an Aboriginal curriculum that is created from within the community, through community participation, and is delivered by community members, for community members. When possible, make use of learning materials and resources that are community-centred and grounded in local language.

\section{Support implementation of technology that is accepted, accessible, suitable and reliable}

Accepted, accessible, suitable and reliable technology must take into consideration local cultural values, social issues, fiscal constraints, technological support and physical space. The 
technology must be introduced appropriately to the community in order for its community benefits to be seen. This will be enhanced by sharing and reflection during the learning process. Ensure the community understands how it can benefit from synchronous technology through enhanced:

- social networking and family connections;

- community capacity building;

- links to other communities; and

- professional training for community mentors.

The community should also be able to choose the types of technology that will be used. It is also important to be aware of the current state of technical equipment and the barriers to computer learning in the community. 6 . Foster intergenerational community involvement

An internal locus of control should reside with the community. Use of online technology should promote a whole-family, whole-community approach and include children through to Elders.

\section{Build positive relationships, mentoring and technical support}

Several types of mentors are needed during the learning process, including onsite mentors, peer mentors, community mentors, Elders, liaison officers, technical support mentors and practitioner mentors. These people play an important role in the retention and motivation of learners. Encourage practitioners and mentors to:

- make time for relationship building and gaining trust;

- gain the community's respect by obtaining permission to be on the land;

- meet with community council regularly;

- have energy to put into engaging learners;

- be approachable;

- support learners academically and emotionally;

- scaffold computer skills;

- show respect for community and members;

- be sensitive towards learners;

- take time to understand the community;

- ensure down-time for themselves to avoid burnout;

- be willing to become active participants in learning; and

- implement technology that is enjoyable to use and relevant to the community.

\section{Promote community-based learning}

Community collaboration which takes a holistic kinship approach allows the community to see the benefits of new technologies. Using Aboriginal strengths (including oral storytelling, song, the Dreamings and language) in this context promotes familiarity and a feeling of comfort for learners, and allows them to work on learning projects in their preferred location and setting.

\section{Cultivate genuine partnerships with government}

Funding is required in all aspects of online learning environments. More work must be done to develop relationships with key stakeholders in order to promote these meaningful, relevant, empowering and real-life online learning opportunities. A third-party may be best-placed to liaise between the community and government services. Ongoing funding is required to support most aspects of online learning environments. Further, online synchronous 
technology can enable community members to represent themselves, in their own voice, directly to government.

\section{Understand community goals, directions and development}

Synchronous learning tools should be used as community-development support-systems, providing links to the outside world and helping to make communities more self-sufficient. They can facilitate understanding of the deep concern many Aboriginal communities have for their children and future generations. This concern is at the core of the community's desire to learn about technology.

\section{Embrace Aboriginal ways of knowing and learning through Elder education}

Elder education is a term the community in this research uses to describe the knowledge, wisdom and experience of Elders that is shared with others. Aboriginal ways of knowing and learning must be considered when creating optimal environments for synchronous learning opportunities. Aboriginal people view lifelong learning and knowledge as a gift that belongs to individuals before they were born and continues throughout their life.

Elders should be considered part of a unique subculture and involved in all stages of new learning environments.

Elder education provides wisdom, reflection on the history of the people and expertise in sharing and passing down this knowledge in an Aboriginal context. It is vital to embrace this knowledge and consult and incorporate these attributes throughout the learning process. Phase 3 supports the decision to include this as an additional design-based principle. It is strongly supported by the literature which overviews Aboriginal ways of knowing. Such research does not blindly accept cultural relevance and Aboriginal ways of knowing as one and the same (Battiste and Henderson, 2000). Henderson (2007) encourages researchers to expand from Western thought and intellect and challenges us to view relationships and deeper expressions of knowledge. Aboriginal knowledge bears a specific and significant role. The creation of this design-based principle on the basis of this research confirms the importance of preserving unique local knowledge, and in turn, preserving culture and community (Butler et al., 2012; Des Jarlais, 2008; Hill et al., 2012; Kinuthia, 2007; Kinuthia and Nkonge, 2005).

\section{Conclusion}

These design-based principles provide sound guidelines for future research that engages Aboriginal adult literacy learners with learning opportunities involving computer technologies.

Literature has shown that the Internet has substantial potential to deliver literacy, essential skills and tertiary training and education to Aboriginal learners who live in remote and isolated communities, providing real-time interaction between instructors and learners. Internet access provides Indigenous learners with an interactive, flexible learning program which allows them to stay in their home communities while meeting education, vocational and personal objectives. Indigenous learners who have participated in online learning initiatives have improved their literacy skills, advanced their technological abilities and increased their potential to contribute to the wellbeing of their communities by being part of an online learning community that many thought was not possible.

The 11 design-based principles presented here will equip practitioners to show respect for Indigenous knowledge and learning practices, engage community leadership and, most importantly, focus on learners' needs. 
Acknowledgements: The author would like to thank the literacy practitioners who gave their time and shared their experiences and expertise, the Digital Bridge Unit Department of Further Education, Employment, Science and Technology in the Government of South Australia for their financial, technical and moral support and most importantly, to the community of Point Pearce, especially the council members and focus group participants, you have shown your strength through this story. Nhagudja!

\section{References}

Alberta's Commission on Learning (2008) 'Turning Vision into Reality: Improve Education Outcomes for Aboriginal Children and Youth.' [online] http:// www.alis.gov.ab.ca/mirror/PDF/CommissionReport.pdf (Accessed May 4, 2008).

Altman, J. C. and Fogarty, W. (2010), "Indigenous Australians as "No Gaps" subjects: Education and development in remote Indigenous Australia', in Snyder, I. and Nieuwenhuysen, J. (Ed.^ Eds), Closing the Gap in Education: Improving Outcomes in Southern World Societies, Monash University Publishing, pp.112-132.

Australian Bureau of Statistics. (2010) National Aboriginal and Torres Strait Islander Social Survey. http://www.abs.gov.au/AUSSTATS/abs@.nsf/ Latestproducts/4714.0Main\%20Features112008?opendocument\&tabnam $\underline{e}=$ Summary \&prodno $=4714.0 \&$ issue $=2008 \&$ num $=\& v i e w=$. (Accessed 19 January 2015)

Australian Bureau of Statistics. (2011) Australian Social Trends. Level of highest educational attainment by Indigenous status. http://www.abs.gov.aul AUSSTATS/abs@.nsf/Lookup/4102.0Main+Features72014?OpenDocume nt. (Accessed 14 January 2015)

Australian Institute for Social Research (2006) The Digital Divide-Barriers to e-learning. Final Report, Digital Bridge Unit, Science Technology and Innovation Directorate.

Bamblett, M. (2005). From welfare to wellbeing: progress in pursuing the wellbeing of Aboriginal and Torres Strait Islander children in Australia. Joining hands across the world for Indigenous children Canada, F. N. C. a. F. C. S. o. Ottawa, First Nations Child and Family Caring Society of Canada: 10-12.

Bang, M., Marin, A., Faber, L. and Suzukovich, E. S. (2013) 'Repatriating Indigenous Technologies in an Urban Indian Community', Urban Education Vol. 48 No. 5, pp.705-733.

Battiste, M. (2008), 'Research ethics for protecting Indigenous knowledge and heritage: Institutional and researcher responsibilities', in Denzin, N. K. et al. (Ed.^Eds), Handbook of critical and Indigenous methodologies, CA: Sage Publications, Thousand Oaks, pp.487-511.

Battiste, M. and Henderson, J. (2000) Protecting Indigenous Knowledge and Heritage: A Global Challenge, Purich Publishing Ltd, Saskatoon.

Brescia, W. and Daily, T. (2007) 'Economic Development and Technology-Skill Needs on American Indian Reservations', American Indian Quarterly Vol. 31 No. 1, pp.23-43.

Butler, J. R. A., Tawake, A., Skewes, T., Tawake, L. and McGrath, V. (2012) 
'Integrating Traditional Ecological Knowledge and Fisheries Management in the Torres Strait, Australia: the Catalytic Role of Turtles and Dugong as Cultural Keystone Species', Ecology and Society Vol. 17 No. 4.

Callan, V. and Bowman, K. (2010) Sustaining E-learning Innovations: A review of the evidence and future directions Australian Flexible Learning Framework. Australian Government. Department of Education, Employment and Workplace Relations, University of Queensland.

Christie, M. (2004) 'Computer Databases and Aboriginal Knowledge', International Journal of Learning in Social Contexts Vol. 1 No., pp.4-12.

Craig Rushing, S. and Stephens, D. (2012) 'Tribal recommendations for designing culturally appropriate technology-based sexual health interventions targeting Native youth in the Pacific Northwest', American Indian and Alaska native mental health research (Online) Vol. 19 No. 1, pp.76-101.

Crossing Boundaries National Council (2005). Aboriginal Voice National Recommendations. From Digital Divide to Digital Opportunity. 5.

Des Jarlais, C. W. (2008) Western structures meet Native traditions: The interfaces of educational cultures, Information Age Publishing, Inc., Charlotte.

Dixon, J., Crooks, H. and Henry, K. (2008) 'Breaking the ice: Supporting collaboration and the development of community online', Canadian Journal of Learning and Technology/La revue canadienne de líapprentissage et de la technologie Vol. 32 No. 2, pp.99-117.

Donovan, M. (2007), 'Can information communication technological tools be used to suit Aboriginal learning pedagogies?', in Dyson, L. E. et al. (Ed. ^Eds), Information technology and Indigenous people, PA: Information Science Publishing, Hershey, pp.93-104.

DuCharme-Hansen, B. and Dupin-Bryant, P. (2005) 'Distance education plans: Course planning for online adult learners', Tec Trends Linking Research and Practice to Improve Learning Vol. 49 No. 2, pp.31-39.

Eady, M.J. (2010) Creating optimal literacy environments using synchronous technologies to Aboriginal adult learners effectively: a Narungga perspective. PhD thesis, University of Wollongong, Wollongong.

Eagles, D., Woodward, P. and Pope, M. (2005) 'Indigenous learners in the digital age: Recognising skills and knowledge'. Paper Presented at Australian Vocational Education and Training Research Association. 16 January 2016. Brisbane, Qld.

El Sayed, F., Soar, J. and Wang, Z. (2011), 'Development of a culturally appropriate interactive multimedia self-paced educational health program for aboriginal health workers' in Enhancing Healthcare Education, Research and Practice Symposium, pp.

English, C. (2013) Good Learning Anywhere - a program by the Sioux-Hudson Literacy Council - wins the NALD Innovative Technology Award [online] https://www.noslangues-ourlanguages.gc.ca/collaborateurs-contributors/ articles/20130930-prix-prize-eng.html (Accessed 20 January).

Fani, T. and Ghaemi, F. (2011) 'Implications of Vygotsky's Zone of Proximal Development (ZPD) in Teacher Education: ZPTD and Self-scaffolding', 
Procedia-Social and Behavioral Sciences Vol. 29 No., pp.1549-1554.

George, P. (1997) Vision: Guiding Native Literacy, Ningwakwe Learning Press, Owen Sound, ON.

Greenall, D. (2005) Formative Evaluation of the Sunchild E-Learning Community, The Conference Board of Canada, Ottawa, ON.

Henderson, L. (2007), 'Theorizing a multiple cultures instructional design model for E-learning and E-teaching', in Edmundson, A. (Ed.^ Eds), Globalized E-Learning Cultural Challenges, Information Science Publishing, Hershey PA, pp.130-153.

Hill, R., Grant, C., George, M., Robinson, C. J., Jackson, S. and Abel, N. (2012) 'A Typology of Indigenous Engagement in Australian Environmental Management: Implications for Knowledge Integration and Socialecological System Sustainability', Ecology and Society Vol. 17 No. 1.

Hughes, M. and Dallwitz, J. (2007), 'Ara Irititja: Towards culturally appropriate IT best practice in remote indigenous Australia', in Dyson, L. E. et al. (Ed. ${ }^{\wedge}$ Eds), Information Technology and Indigenous People Information Science Publishing, Hershey, PA, pp.146-158.

Kinuthia, W. (2007), 'Instructional design and technology implications for Indigenous knowledge: Africa's introspective', in Dyson, L. E. et al. (Ed. ${ }^{\wedge}$ Eds), Information Technology and Indigenous People Information Science Publishing, Hershey, PA, pp.105-116.

Kinuthia, W. and Nkonge, B. (2005), 'Perspectives on culture and e-learning convergence' in World Conference on E-Learning in Corporate, Government, Healthcare, and Higher Education, pp.

Kral, I. (2010) Plugged in: Remote Australian Indigenous Youth and Digital Culture. CAEPR Working Paper No. 69/2010, Centre for Aboriginal Economic Policy Research. The Australian National University

McDonald, R., O'Callaghan, K., Walker, M. and Fyffe, J. (2006) Engagement Project Report, Australian Government. Department of Education, Science and Training, Canberra ACT.

McGlusky, N. and Thucker, L. (2006) Literacy support for Indigenous people: Current systems and practices in Queensland, Australian Government. Department of Education, Science and Training, Adelaide.

Miller, C. and Harris, L.-A. (2005) Aspects of training that meet Indigenous Australians aspirations: A systematic review of research Support document, National Centre for Vocational Education, Adelaide, SA.

O'Callaghan, K. (2005) Indigenous vocational education and training. At a glance, National Centre for Vocational Education Research, Adelaide, SA.

Porter, P. and Sturm, M. (2006) Crossing the Great Divides: Distance learning and flexible delivery in Adult Basic Education, Centre AlphaPlus Centre, Toronto, ON.

Reeves, T. C. (2006), 'Design research from a technology perspective', in Akker, J. et al. (Ed.^Eds), Educational Design Research, Routledge, London, UK, pp.52-66. 
Rennie, E., Crouch, A., Wright, A. and Thomas, J. (2013) 'At home on the outstation: Barriers to home Internet in remote Indigenous communities', Telecommunications Policy Vol. 37 No. 6-7, pp.583-593.

Sawyer, G. (2004) New Practices in Flexible Learning. Closing the Digital Divide: Increasing education and training opportunities for Indigenous students in remote areas, Australian National Training Authority.

Smith, M., Biemmi Beurteaux, E. and Trinidad, S. (2008) 'Blogging in the Bush: Using social computing to enhance adult literacy in remote Western Australia'. Paper Presented at Computers in Education Conference. Canberra, ACT.

Tankard, T. and O'Kelly, C. (2009), 'Learning pathways-a diverse, equitable and flexible Indigenous curriculum' in 7th Australian Vocational Education and Training Research Association Conference, pp.

Taylor, A. (2012) 'More than Mobile: Migration and Mobility Impacts from the 'Technologies of Change' for Aboriginal Communities in the Remote Northern Territory of Australia', Mobilities Vol. 7 No. 2, pp.269-294.

United Nations (2009) State of the World's Indigenous Peoples, Department of Economic and Social Affairs New York.

United Nations Educational Scientific and Cultural Organization (2006) Education for All. Literacy for Life, Education for All Monitoring Report, Paris, France.

van den Akker, J., Gravemeijer, K., McKenney, S. and Nieveen, N., Eds.), (2006) Educational Design Research. Routledge, Oxon, UK.

Wang, F. and Hannafin, M. J. (2005) 'Design-Based Research and TechnologyEnhanced Learning Environments', Educational Technology Research and Development Vol. 53 No. 4, pp.5-24. 